\title{
Evaluation of intrabony defects treated with platelet-rich fibrin or autogenous bone graft: A comparative analysis
}

\author{
Ashish Mathur ${ }^{1}$, Vivek Kumar Bains ${ }^{1}$, Vivek Gupta ${ }^{2}$, Rajesh Jhingran ${ }^{1}$, G. P. Singh ${ }^{1}$
}

Correspondence: Dr. Vivek Kumar Bains,

Email: doc_vivek76@yahoo.co.in

'Department of Periodontology, Saraswati Dental College, Lucknow, Uttar Pradesh, India,

${ }^{2}$ Rama Dental College Hospital and Research Centre, Kanpur, Uttar Pradesh, India

\begin{abstract}
Objective: The primary objective of this study was to compare clinically and radiographically the efficacy of autologous platelet rich fibrin (PRF) and autogenous bone graft $(\mathrm{ABG})$ obtained using bone scrapper in the treatment of intrabony periodontal defects. Materials and Methods: Thirty-eight intrabony defects (IBDs) were treated with either open flap debridement (OFD) with PRF or OFD with ABG. Clinical parameters were recorded at baseline and 6 months postoperatively. The defect-fill and defect resolution at baseline and 6 months were calculated radiographically (intraoral periapical radiographs [IOPA] and orthopantomogram [OPG]). Results: Significant probing pocket depth (PPD) reduction, clinical attachment level (CAL) gain, defect fill and defect resolution at both PRF and ABG treated sites with OFD was observed. However, inter-group comparison was non-significant $(P>0.05)$. The bivariate correlation results revealed that any of the two radiographic techniques (IOPA and OPG) can be used for analysis of the regenerative therapy in IBDs. Conclusion: The use of either PRF or ABG were effective in the treatment of three wall IBDs with an uneventful healing of the sites.
\end{abstract}

Key words: Autogenous bone graft, blood platelets, chronic periodontitis, wound healing

\section{INTRODUCTION}

Owing to their osteogenetic potential, autogenous bone grafts (ABGs) have been widely used in periodontics for the treatment of intrabony defects (IBDs) and can be harvested from either extraoral or intraoral donor sites. Among the various methods of harvesting intraoral ABG, use of bone scraper is less aggressive. Further, the autogenous graft material is obtained from the adjacent areas of actual graft site, thus avoiding second intra or extra oral surgical sites and attendant morbidities. This autogenous cortical bone graft mixed with blood is sufficient to augment localized osseous defects. ${ }^{[1]}$

Second-generation platelet concentrate, platelet rich fibrin (PRF), developed in France by Choukroun et al..$^{[2]}$ in 2001, is a fibrin-matrix in which platelet, cytokines and cells are entrapped that are released after a certain time and can serve as resorbable membrane. PRF is considered to be a healthy biomaterial, and was initially used in oral implantology by its promoters, and presently, its application has been advocated in various disciplines of dentistry. ${ }^{[3]}$ The present study was conducted to compare and evaluate autologous PRF and ABG obtained using the bone scrapper in the treatment of intrabony periodontal defects clinically and radiographically.

\section{MATERIALS AND METHODS}

The present randomized clinical study was conducted between December 2010 and June 2013. Ethical clearance was obtained from institutional ethical committee.

\footnotetext{
How to cite this article: Mathur A, Bains VK, Gupta V, Jhingran R, Singh GP. Evaluation of intrabony defects treated with platelet-rich fibrin or autogenous bone graft: A comparative analysis. Eur J Dent 2015;9:100-8.

Copyright $\odot 2015$ Dental Investigations Society.

DOI: $10.4103 / 1305-7456.149653$
} 
After ethical approval, 25 patients (14 males and 11 females) received verbal information regarding participation, and written informed consent obtained for participation in the study. Compliant/motivated nonsmoker, nonalcoholic patients with no contributory medical history and suffering from generalized moderate to severe chronic periodontitis were selected amongst the patients visiting the Department of Periodontology for the present randomized clinical study with following inclusion and exclusion criteria:

\section{Inclusion criteria}

(1) Patients who were diagnosed as from moderate to severe generalized chronic periodontitis having minimum twenty teeth. (2) Patients of both sexes with age group of $30-65$ years (mean age $39.66 \pm 5.72$ years) having at least one IBD with probing pocket depth(PPD) $\geq 5 \mathrm{~mm}$, radiographic defect on intraoral periapical radiographs (IOPA) of $\geq 3 \mathrm{~mm}$ and predominantly three wall interproximal IBDs as assessed from bone sounding (transgingival probing [TGP]) after scaling and root planing. (3) Compliant patients with full mouth plaque score $<1$ (good oral hygiene) during phase 1 therapy [Figure 1].

\section{Exclusion criteria}

(1) Systemic diseases that contraindicate any periodontal surgery. (2) Any patient with known allergy to local anesthesia, antiseptics, antibiotics and chlorhexidine. (3) Pregnant and lactating mothers. (4) Patients having received any medication (antibiotics, anti-inflammatory, hormonal drugs, contraceptives, anticoagulants and anti-aggregans etc.) for last 6 months affecting the periodontal status. (4) Third molars, $>2^{\circ}$ mobile $^{[4]}$ and inadequate endodontic treatment/restoration were excluded.

\section{Initial therapy}

Before surgery, each patient was given careful instructions regarding proper oral hygiene measures. A full mouth supra and subgingival scaling and root planing were performed using an ultrasonic device (Cavitron ${ }^{\mathrm{TM}}$ Bobcat ${ }^{\mathrm{TM}}$ Pro Ultrasonic scaler, Dentsply USA) and hand instruments (Gracey curettes, Hu-Friedy USA). Occlusal adjustment was done if required.

\section{Procurement of platelet-rich fibrin}

Platelet rich fibrin was prepared according to the protocol developed by Choukouran et al. ${ }^{[5]}$ (3000 RPM for $10 \mathrm{~min}$ ) using REMI Laboratories (India) table top centrifuge [Figures 2 and 3].

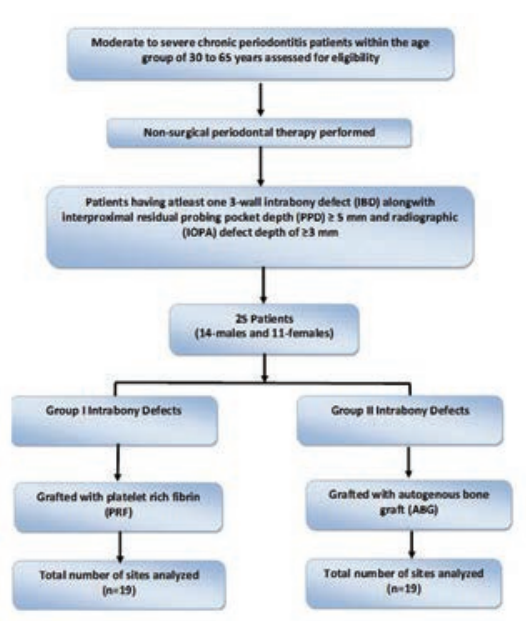

Figure 1: Flowchart showing study design

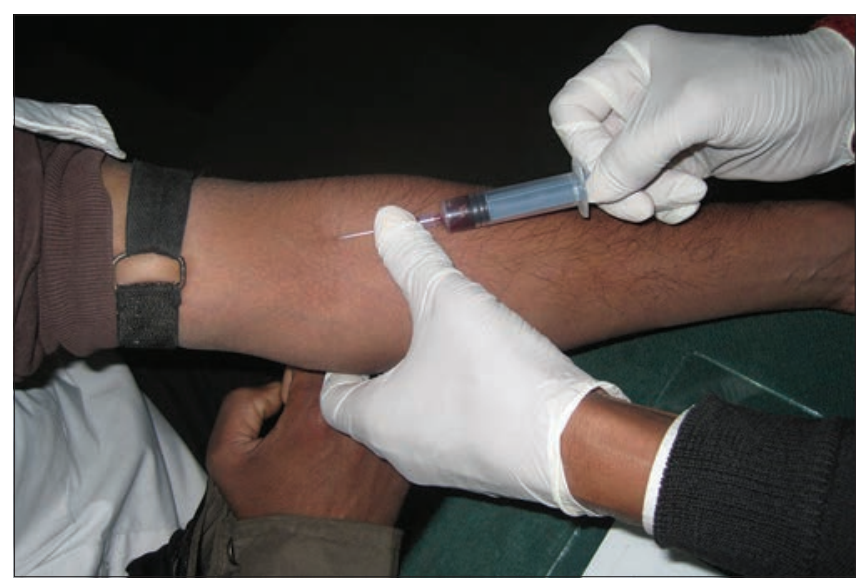

Figure 2: Drawing of blood for preparation of platelet rich fibrin

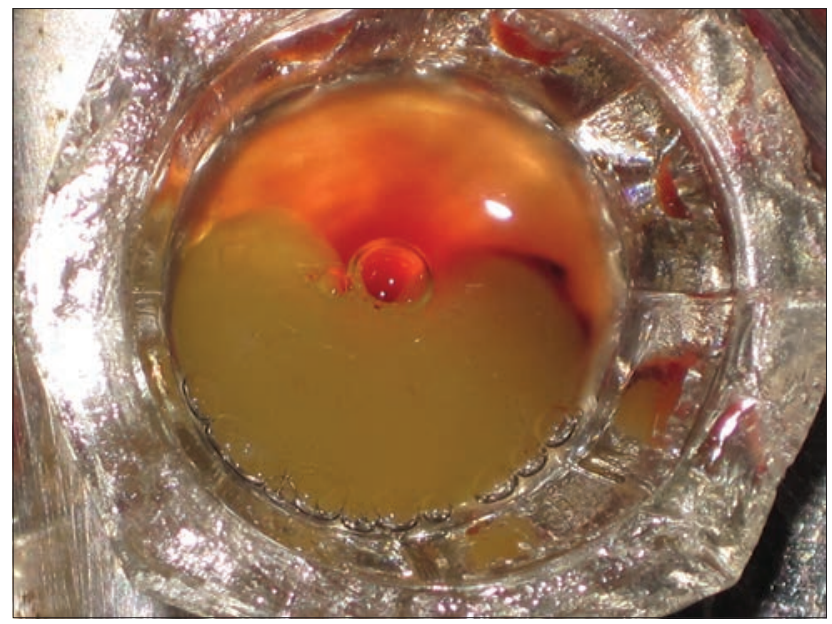

Figure 3: Platelet rich fibrin obtained after centrifuging the blood

\section{Procurement of ABG}

The 502 expanded bone grafter (Salvins Dental Specialities Inc, NC USA) was used for bone removal and procuring $\mathrm{ABG}^{[6]}$ [Figures 4 and 5]. 


\section{Surgical procedure}

Four to eight weeks after presurgical therapy, a periodontal evaluation was performed to confirm the desired sites for the study. An intraoral asepsis was performed by preprocedural mouth rinse by $10 \mathrm{ml}$ of $0.2 \%$ chlorhexidine gluconate (Hexidine $0.2 \%$, ICPA, India) solution. The extraoral asepsis was carried by swabbing with $5 \%$ povidine-iodine solution (Betadine, Win Medicare, India). After the administration of local anesthesia (Xicaine 2\% Adrenaline 1:80,000, ICPA, India), buccal and lingual/palatal sulcular incision were made and mucoperiosteal flaps were reflected. Care was taken to preserve as much of the interproximal soft tissue as possible. After the flap was reflected, the osseous defect was exposed, and thorough surgical debridement of the soft and the hard tissues was carried out using Gracey's area specific curettes. Surgical site was irrigated copiously using normal saline. The selected sites were randomly

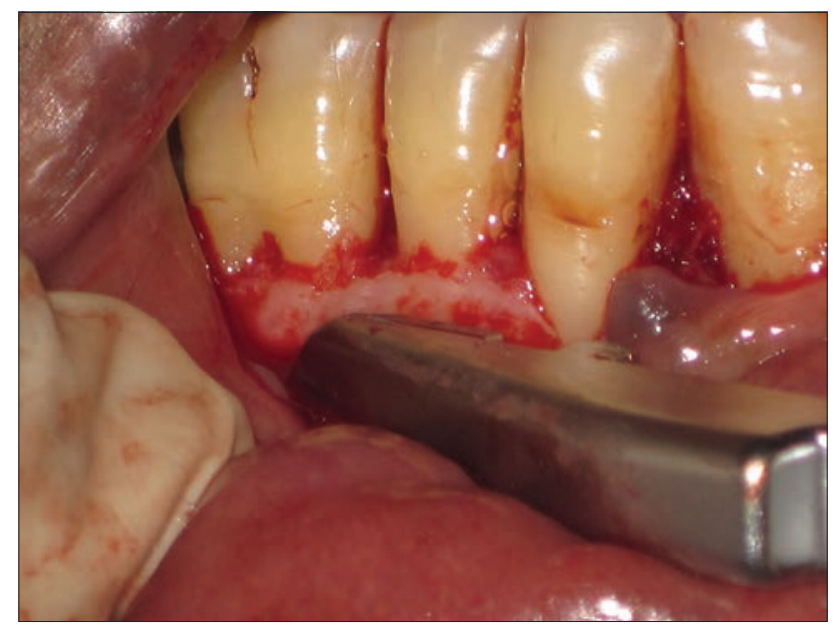

Figure 4: Procurement of autogenous bone graft by bone scrapper

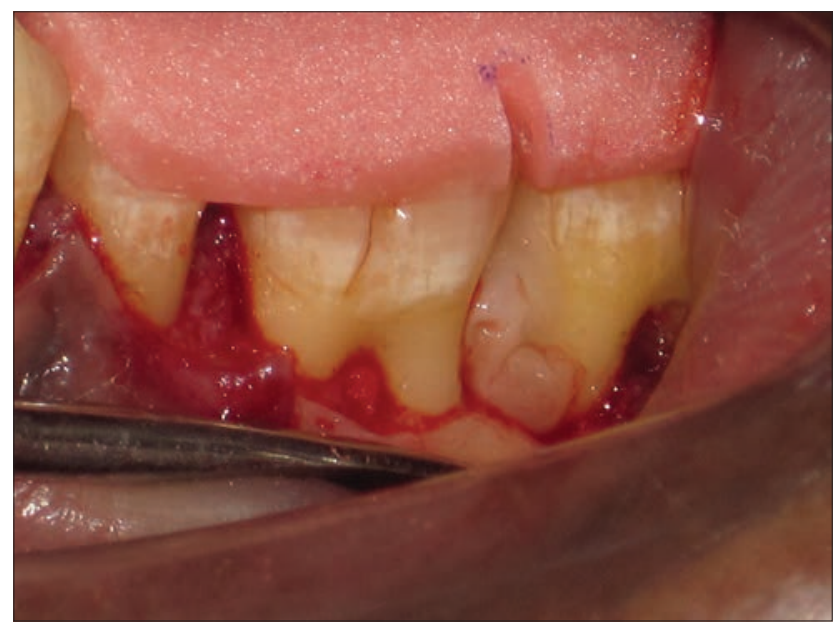

Figure 6: Platelet rich fibrin placed in intrabony defects (Group I) divided (by coin-toss method) into two experimental groups: Group I IBDs $(n=19)$ treated open flap debridement (OFD) and filled with PRF (OFD with PRF) [Figure 6]; and Group II IBDs $(n=19)$ treated OFD and filled with ABG (OFD with ABG) [Figure 7]. The mucoperiosteal flaps were repositioned and secured using 4-0 interrupted direct loop silk sutures, and the area was protected by noneugenol dressing (CoePak, GC America, Chicago, IL, USA).

\section{Postoperative care}

All the patients were given written postoperative instructions and medication (amoxicillin $500 \mathrm{mg}$ 3 times a day for 7 days and paracetamol 500 mg every 6 hourly for 3 days). Patients were instructed to report after 2 weeks. The periodontal dressing and the sutures were removed 2 weeks postoperatively. Surgical sites were gently cleansed with $0.12 \%$ chlorhexidine digluconate, and patients were instructed regarding gentle brushing with a soft toothbrush. Oral hygiene instructions were reinforced every 2 months and supra gingival scaling was done if required. No sub-gingival instrumentation was attempted at any of these appointments.

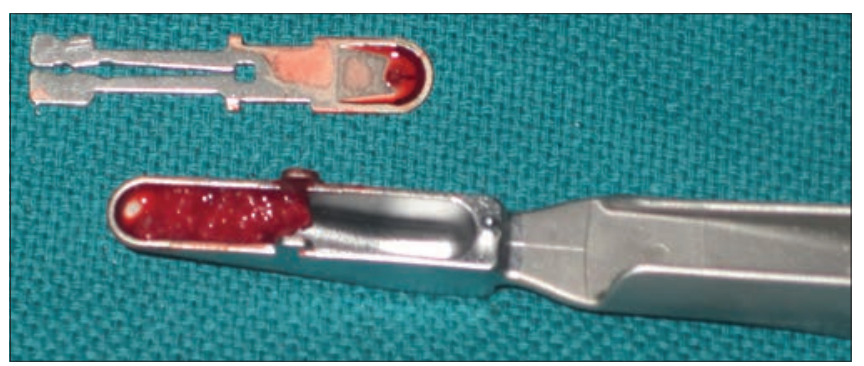

Figure 5: Autogenous bone graft collected in bone scrapper

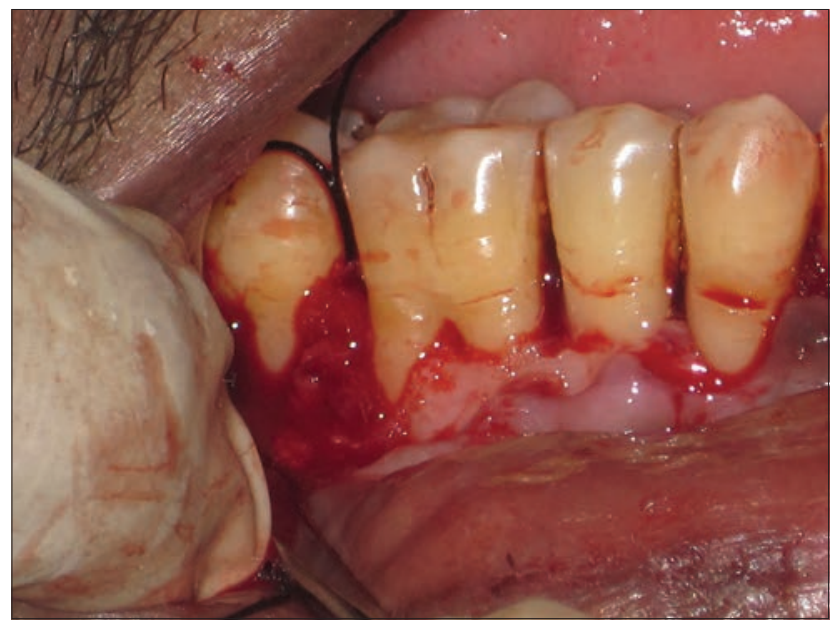

Figure 7: Autogenous bone graft obtained placed in intrabony defect (Group II) 


\section{Clinical parameters}

Clinical parameters were recorded using a $25 \mathrm{~mm}$, \#30 silver cone or UNC-15 probe with stopper from a fixed reference point (FRP) on the upper border of customized acrylic stent with a guiding groove [Figure 8]. Plaque index (PI), ${ }^{[7]}$ gingival index $(\mathrm{GI}),{ }^{[8]}$ position of gingival margin $(\mathrm{GM}), \mathrm{PPD}$, clinical attachment level (CAL), cementoenamel junction (CEJ), IBD depth (FRP to BD: Distance of the base of IBD from FRP on the stent) and level of adjacent alveolar crest (FRP to AC: The distance from FRP on the stent to the alveolar crest) were recorded at baseline and 6 months post operatively. All the customized acrylic stents ${ }^{[9]}$ were stored on the prepared study casts throughout the study period to minimize distortion. Endobloc (Maillefer Dentsply, Switzerland) was used for the measurement of the silver cone.

For obtaining hard tissue measurements, TGP or sounding of the IBDs was carried out under local anesthesia. To verify the values of TGP, they were reevaluated after flap reflection. TGP of the alveolar bone levels gave an accurate indication of the bone level measured at surgery. ${ }^{[10]}$ Six month post-operatively, measurements of the hard tissue parameters by TGP were recorded and included for the study.

\section{Radiographic assessment}

Radiographic measurements (IOPA and orthopantomogram [OPG]) observed were recorded at a single reference center by blind examiner from the Department of Oral Medicine and Radiology, and were evaluated at baseline and at 6 months. The CEJ was identified as the difference in the radiopacity of the enamel and the cementum. The most apical

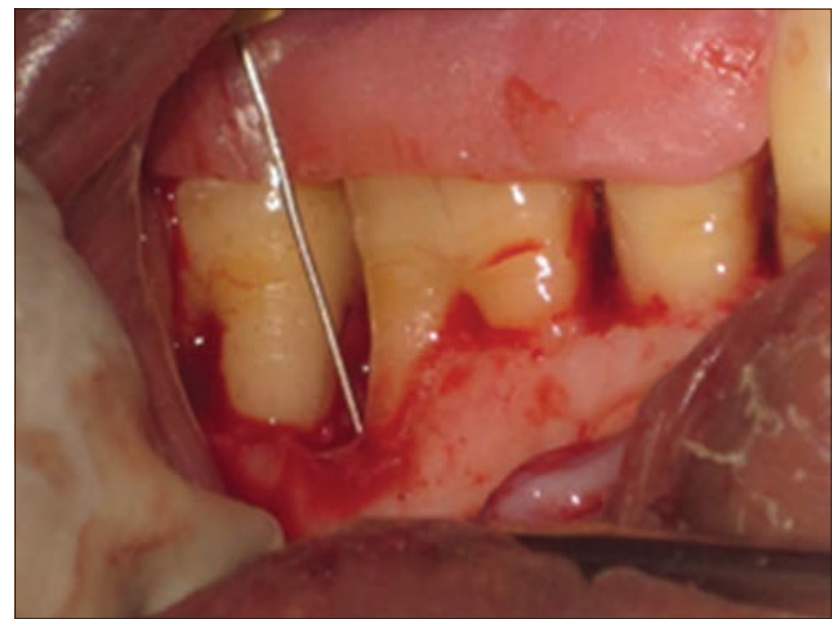

Figure 8: Clinical parameters were recorded using a $25 \mathrm{~mm}$, \#30 silvercone on the upper border of customized acrylic stent with a guiding groove extension of an interproximal restoration was used when present instead of CEJ. The most coronal area where the periodontal ligament maintained an even width was identified as the defect depth. The crossing of the silhouette of the alveolar crest with the root surface was defined as alveolar crest. ${ }^{[11]}$

Intraoral periapical radiographs were taken by long cone/extension cone paralleling technique using a Rinn positioning device (Dentsply, USA) and a size 2E speed Kodak IOPA X-ray film in a Villa (Italy) $\mathrm{X}$-ray unit $(70 \mathrm{kVp}, 15 \mathrm{~mA}, 0.6 \mathrm{mAs})$. The IOPA thus obtained were superimposed with a nonmetallic grid with calibrations of $1 \times 1 \mathrm{~mm}^{2}$ [Figure 9]. Following radiographic parameters were measured by means of counting the squares on the calibrated grid: Level of alveolar crest (vertical distance from the CEJ to the crest of the alveolar bone [CEJ to $\mathrm{AC}$ ]); base of IBDs (vertical distance from the CEJ to the crest of the base of the IBD [CEJ to BD]); vertical distance from the crest of the alveolar bone to the base of the defect (VD); defect fill was calculated by the difference in the change in the base of IBD between baseline and follow up (6 months); and defect resolution was calculated by the difference in the change in vertical distance from the crest of the alveolar bone to the base of the defect between baseline and follow-up. ${ }^{[12]}$

Orthopantomogram were made for all the patients at baseline and at the end of 6 months using Kodak 8000C Digital Panoramic and Cephalometric System (Carestream Health, Inc. NY) and images were analyzed using Kodak dental imaging software (Version 6-12.11.0) on computer screen by Radiographic Technician in Radiology Department [Figure 10]. The following readings were

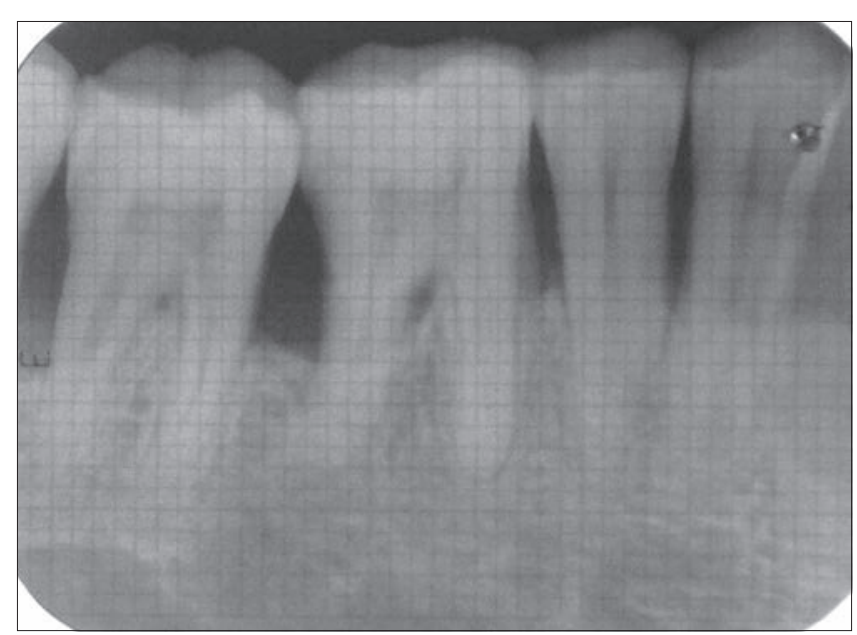

Figure 9: Intraoral periapical radiographs with superimposed with a non-metallic grid with calibrations of $1 \times 1 \mathrm{~mm}^{2}$ 
made level of alveolar crest (distance from the CEJ to the crest of the adjacent alveolar bone [CEJ to AC]); base of IBDs (distance from the CEJ to the crest of the base of the IBD [CEJ to $\mathrm{BD}]$ ); distance of alveolar crest to base of IBD (AC to BD); defect fill was calculated by the difference in the change in the base of IBD (CEJ to BD) between baseline and follow up ( 6 months) and defect resolution was calculated by the difference in the change in distance of alveolar crest to base of defect (AC to BD) between baseline and follow up (6 months). ${ }^{[12]}$

\section{Statistical analysis}

All the clinical and radiographic parameters were always recorded in duplicate, and the mean values were taken into records. The statistical analysis was performed using Statistical Package for Social Sciences version 15.0 statistical analysis software (SPSS 15.0 for Windows, Chicago, SPSS Inc). Bivariate correlation was used to obtain a level of correlation between two variables using Pearson's correlation coefficient.

\section{RESULTS}

All the subjects reported uneventful healing at all the sites $(n=38)$. The results obtained depicts changes in both soft and hard tissue parameters after 6 months for Group I (OFD with PRF) and Group II (OFD with ABG) IBDs, both clinically as well as radiographically [Table 1]. There was significant mean PPD reduction and CAL gain, in both the PRF treated group $(2.67 \pm 1.29 \mathrm{~mm}, 2.53 \pm 1.06 \mathrm{~mm})$ and the ABG treated group $(2.4 \pm 1.06 \mathrm{~mm}, 2.67 \pm 1.63 \mathrm{~mm})$, respectively. Furthermore, significant defect fill was observed in the both PRF $(2.93 \pm 1.79 \mathrm{~mm}, 3.94 \pm 3.56 \mathrm{~mm}$ and $2.01 \pm 2.09 \mathrm{~mm})$ and ABG $(2.66 \pm 1.84 \mathrm{~mm}$, $1.76 \pm 0.83 \mathrm{~mm}$ and $1.02 \pm 0.58 \mathrm{~mm}$ ) treated groups, by TGP, IOPA and OPG, respectively. Defect resolution of $1.73 \pm 1.62 \mathrm{~mm}$ and $1.37 \pm 1.93 \mathrm{~mm}$ was observed in PRF treated sites whereas defect resolution of $1.53 \pm 0.92 \mathrm{~mm}$ and $1.30 \pm 0.95 \mathrm{~mm}$ was observed in ABG treated sites, respectively by IOPA and OPG.

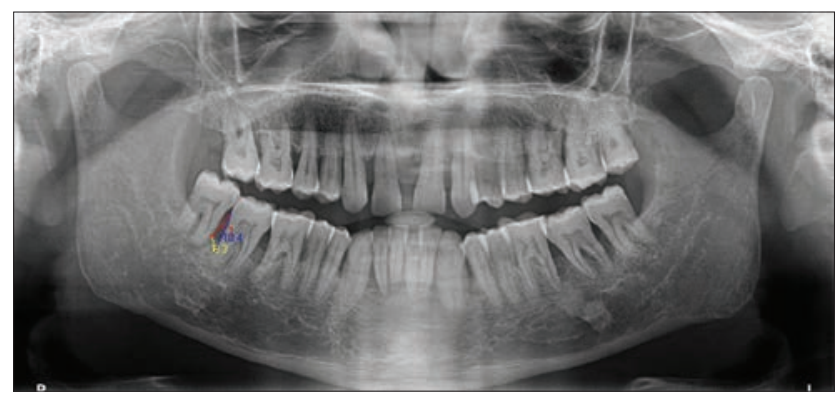

Figure 10: Orthopantomogram

\section{Inter-group comparison}

No significant difference in mean change after intervention between the two groups was observed for clinical parameters (PI, GI, PPD, CAL, AC, and $\mathrm{BD}$ level). Among different radiographic methods of measurements, a significant difference between two groups was observed for mean change in BD level (by IOPA) which was found to be higher in Group I (OFD with PRF) when compared to Group II (OFD with $A B G$ ), representing more defect fill (mean change in the base of IBD) for Group I (OFD with PRF). Statistically significant $(P<0.05)$ difference between two groups for mean change in AC level was observed due to significant reduction in AC level in Group II (OFD with $A B G$ ) when compared to non-significant gain in Group I (OFD with PRF) with OPG techniques [Table 2].

Correlation between clinical and radiological results A quantitative bivariate correlation between clinical and radiological findings shows that scores obtained for mean change in base of IBD (BD) level was moderate $(r=0.5-0.7)$. The correlation between the clinical and the IOPA $(r=0.69)$ measurements for BD levels reveals slight stronger correlation, followed by OPG $(\mathrm{r}=0.65)$ [Figure 11].

\section{DISCUSSION}

Present study was carried out as a single centered randomized clinical trial to compare clinically and radiographically, the effectiveness of OFD with PRF (Group I) or ABG (Group II). No uneventful healing and postoperative complication was observed in any of the studied groups. The uneventful healing in patients was in agreement with various previous

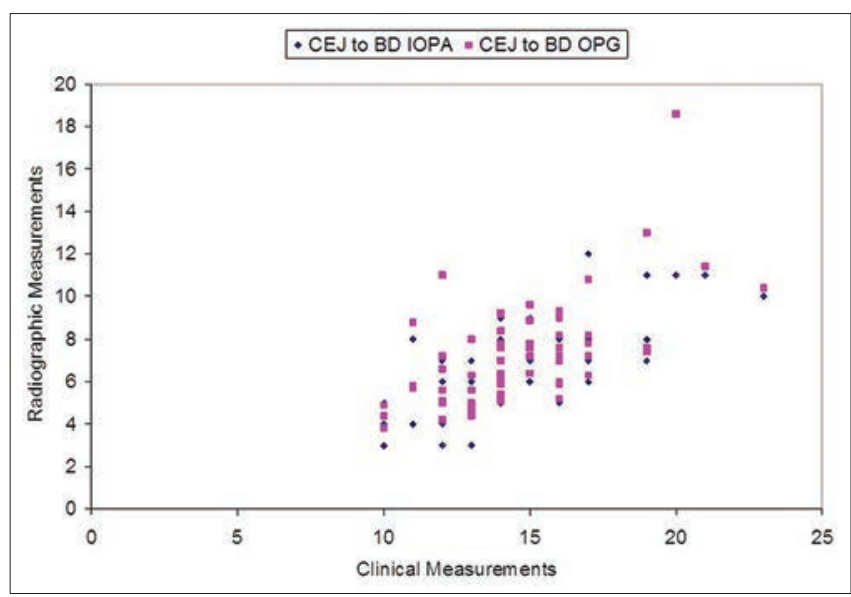

Figure 11: Correlation between mean change in base of intrabony defect clinically and two radiographic techniques (intra oral periapical and orthopantomogram) 
Mathur, et al.: PRF and ABG in intrabony defect treatment

\begin{tabular}{|c|c|c|c|c|c|c|c|c|}
\hline \multirow[t]{3}{*}{ Parameter } & \multicolumn{4}{|c|}{ Group I (OFD with PRF) } & \multicolumn{4}{|c|}{ Group II (OFD with ABG) } \\
\hline & \multicolumn{2}{|c|}{ Mean $\pm S D$} & \multicolumn{2}{|c|}{$\begin{array}{l}\text { Significance } \\
\text { of difference* }\end{array}$} & \multicolumn{2}{|c|}{ Mean \pm SD } & \multicolumn{2}{|c|}{$\begin{array}{l}\text { Significance } \\
\text { of difference* }\end{array}$} \\
\hline & $\begin{array}{c}\text { Before } \\
\text { intervention }\end{array}$ & $\begin{array}{l}6 \text { months after } \\
\text { intervention }\end{array}$ & $z$ & $P$ & $\begin{array}{c}\text { Before } \\
\text { intervention }\end{array}$ & $\begin{array}{l}6 \text { months after } \\
\text { intervention }\end{array}$ & $Z$ & $P$ \\
\hline $\mathrm{PI}$ & $0.74 \pm 0.12$ & $0.72 \pm 0.13$ & 0.577 & 0.564 & $0.79 \pm 0.12$ & $0.75 \pm 0.12$ & 1.190 & 0.234 \\
\hline GI & $1.13 \pm 0.13$ & $0.98 \pm 0.09$ & 3.109 & 0.002 & $1.10 \pm 0.14$ & $1.01 \pm 0.09$ & 2.365 & 0.018 \\
\hline Gingival recession (FRP to GM) & $9.40 \pm 1.76$ & $9.47 \pm 1.88$ & 0.577 & 0.564 & $10.07 \pm 1.10$ & $10.33 \pm 1.50$ & 1.300 & 0.194 \\
\hline PPD & $7.67 \pm 2.26$ & $5.00 \pm 1.25$ & 3.474 & 0.001 & $7.93 \pm 2.28$ & $5.53 \pm 1.81$ & 3.471 & 0.001 \\
\hline CAL & $6.87 \pm 2.75$ & $4.33 \pm 2.50$ & 3.434 & 0.001 & $7.87 \pm 3.38$ & $5.20 \pm 2.43$ & 3.438 & 0.001 \\
\hline AC level on IOPA & $11.67 \pm 0.98$ & $11.67 \pm 0.98$ & 0 & 1 & $12.47 \pm 2.67$ & $12.67 \pm 1.63$ & 1.069 & 0.285 \\
\hline Base of defect on IOPA & $15.60 \pm 2.13$ & $12.67 \pm 1.84$ & 3.436 & 0.001 & $16.46 \pm 2.98$ & $13.80 \pm 1.97$ & 3.470 & 0.001 \\
\hline CEJ to AC on IOPA & $4.40 \pm 1.88$ & $4.27 \pm 1.83$ & 1.000 & 0.317 & $4.73 \pm 1.33$ & $5.00 \pm 1.25$ & 2.000 & 0.046 \\
\hline CEJ to BD on IOPA & $7.47 \pm 2.39$ & $5.20 \pm 1.61$ & 3.408 & 0.001 & $7.53 \pm 1.64$ & $6.27 \pm 1.53$ & 3.411 & 0.001 \\
\hline $\begin{array}{l}\text { VD between base of defect } \\
B D \text { and } A C \text { on IOPA }\end{array}$ & $3.07 \pm 1.91$ & $1.33 \pm 1.40$ & 2.930 & 0.003 & $2.80 \pm 1.42$ & $1.27 \pm 0.96$ & 3.578 & $<0.001$ \\
\hline CEJ to $A C$ on OPG & $5.03 \pm 1.79$ & $5.03 \pm 1.75$ & 0.322 & 0.748 & $5.19 \pm 1.24$ & $5.43 \pm 1.24$ & 3.063 & 0.002 \\
\hline CEJ to BD on OPG & $8.25 \pm 3.60$ & $6.24 \pm 1.98$ & 3.409 & 0.001 & $7.78 \pm 1.71$ & $6.76 \pm 1.52$ & 3.411 & 0.001 \\
\hline$A C$ to $B D$ on OPG & $3.25 \pm 2.97$ & $1.88 \pm 1.85$ & 2.929 & 0.003 & $2.61 \pm 1.44$ & $1.31 \pm 0.87$ & 3.411 & 0.001 \\
\hline
\end{tabular}

Table 2: Comparison of mean change in clinical and radiographic parameters for group I (OFD with PRF) and group II (OFD with ABG)

\begin{tabular}{|c|c|c|c|c|c|c|}
\hline \multirow[t]{3}{*}{ Parameter } & \multicolumn{4}{|c|}{$n=19$} & \multirow{2}{*}{\multicolumn{2}{|c|}{$\begin{array}{l}\text { Significance of } \\
\text { difference }^{* *}\end{array}$}} \\
\hline & \multicolumn{2}{|c|}{ Group I } & \multicolumn{2}{|c|}{ Group II } & & \\
\hline & Mean change & SD & Mean change & SD & $Z$ & $P$ \\
\hline $\mathrm{PI}$ & -0.02 & 0.11 & -0.04 & 0.12 & 0.336 & 0.775 \\
\hline $\mathrm{GI}$ & -0.15 & 0.12 & -0.09 & 0.12 & 1.266 & 0.233 \\
\hline Gingival recession (FRP to GM) & 0.07 & 0.46 & 0.27 & 0.80 & 0.504 & 0.713 \\
\hline PPD & -2.67 & 1.29 & -2.40 & 1.06 & 0.545 & 0.624 \\
\hline CAL & -2.53 & 1.06 & -2.67 & 1.63 & 0.257 & 0.806 \\
\hline AC level on IOPA & 0.00 & 0.38 & 0.20 & 1.70 & 1.437 & 0.233 \\
\hline Base of defect on IOPA & -2.93 & 1.79 & -2.66 & 1.84 & 0.813 & 0.461 \\
\hline CEJ to AC on IOPA & -0.13 & 0.52 & 0.27 & 0.46 & 2.274 & 0.148 \\
\hline CEJ to BD on IOPA & -3.94 & 3.56 & -1.76 & 0.83 & 2.440 & 0.026 \\
\hline $\begin{array}{l}\text { VD between base of defect } \\
B D \text { and } A C \text { on IOPA }\end{array}$ & -1.73 & 1.62 & -1.53 & 0.92 & 0.910 & 0.412 \\
\hline CEJ to $A C$ on OPG & -0.01 & 0.10 & 0.24 & 0.24 & 2.492 & 0.013 \\
\hline CEJ to BD on OPG & -2.01 & 2.09 & -1.02 & 0.58 & 1.124 & 0.267 \\
\hline$A C$ to $B D$ on $O P G$ & -1.37 & 1.93 & -1.30 & 0.95 & 0.062 & 0.967 \\
\hline
\end{tabular}

studies of Sharma and Pradeep, ${ }^{[13]}$ Thorat et al. ${ }^{[14]}$ and Cyrana and Banach, ${ }^{[15]}$ thus supporting the excellent biocompatible and enhanced wound healing properties of ABG and PRF. Plaque, infection and smoking are important factors that were shown to significantly influence the outcomes of regenerative periodontal surgery. ${ }^{[16,17]}$ Statistically non-significant $(P>0.05)$ change in mean PI and GI for both the groups, represents meticulous oral hygiene and compatible behavior of the patients. Because this study excludes smokers, and only includes patients who were able to maintain acceptable oral hygiene, it may be assumed that the careful patient selection was also responsible for the positive outcomes obtained in both groups. 
Concurrent to previously published studies, in present study also non-significant changes in the level of GM was observed after 6 months in the PRF treated sites. ${ }^{[13,14]}$ Inter-group comparison revealed, more gingival recession in Group II (OFD with ABG) as compared to Group I (OFD with PRF), but the difference was statistically non-significant. Statistically highly significant reduction in the PPD and gain in CAL in the Group I (OFD with PRF) were similar to the earlier published reports. ${ }^{[13,14]}$ However, in contrast with Sharma and Pradeep ${ }^{[13]}$ our study did not report any such coronal movement. This may be due to the procedural difference in the placement of the PRF. In present study, to simulate ABG placement, no attempts were made to cover the IBD by the PRF membrane. The present study was designed to evaluate the efficacy of the PRF as a graft instead as a GTR membrane, as advocated by Sharma and Pradeep. ${ }^{[13]}$ The PRF clot with PRF gel obtained were directly placed into the IBD as a graft to maintain adequate matrix volume.

No statistically significant mean change in the level of AC was observed for both Group I (OFD with PRF) and Group II (OFD with ABG) when recorded clinically by TGP at follow up (6 months), however AC resorption was observed in Group II (OFD with ABG) by radiographic evaluation. Radiographic interpretation of the AClevel revealed a nonsignificant gain with IOPA and OPG in Group I (OFD with PRF); whereas for Group II (OFD with ABG) statistically significant resorption with IOPA and OPG, was observed. The correlative interpretation between the clinical and radiographic measurements of AC levels shows some amount of resorption of $A C$ in the cases where ABG were placed in the IBDs, in contrast to the PRF treated sites. Surgical intervention using full thickness flap elevation may contribute to such results. ${ }^{[18]}$ Shirmohammadi et al..$^{[19]}$ also reported significant $A C$ resorption of $0.53 \pm 0.51 \mathrm{~mm}$ in $\mathrm{ABG}$ group. Further, the outcome of autogenous cortical bone shavings (ABG) obtained by bone scrapper require re-establishment of vascularity from the recipient site, as well as resorption of the necrotic graft material that act as a stimulus or trigger for the new bone formation. ${ }^{[20]}$ In contrast, the PRF addition in Group I (OFD with PRF) might decrease many harmful effects due to inflammatory processes that are inherent to the surgical act itself, mainly by correcting certain destructive and noxious excesses during the healing process of wounded tissues. ${ }^{[21]}$

Statistically highly significant defect fill, that is, the mean change in the BD level was observed in Group I (OFD with PRF) and Group II (OFD with ABG) after 6 months of intervention. The mean IBD fill were $2.93 \pm 1.79 \mathrm{~mm}$, $3.94 \pm 3.56 \mathrm{~mm}$ and $2.01 \pm 2.09 \mathrm{~mm}$ respectively by TGP, IOPA and OPG for Group I (OFD with PRF), whereas the mean IBD fill was $2.66 \pm 1.84 \mathrm{~mm}, 1.76 \pm 0.83 \mathrm{~mm}$ and $1.02 \pm 0.58 \mathrm{~mm}$ respectively observed by TGP, IOPA and OPG for Group II (OFD with ABG). Shetty et al. ${ }^{[12]}$ also reported significant defect fill in PRP treated IBDs, whereas Cyrana and Banach ${ }^{[15]}$ and Shirmohammadi et al. ${ }^{[19]}$ reported statistically significant defect fill ABG treated IBDs.

Defect resolution recorded by radiographic measurements, that is, change in the vertical height of IBD taken by the IOPA (VD) and change in the distance from the AC to BD on OPG revealed a highly significant difference for Group I (OFD with PRF) and for Group II (OFD with ABG). Thorat et al..$^{[14]}$ and Sharma and Pradeep ${ }^{[13]}$ reported significant defect resolution in PRF treated IBDs. Shirmohammadi et al. ${ }^{[19]}$ reported defect resolution of $2.92 \pm 0.5 \mathrm{~mm}$ on IOPAs, whereas $3.21 \mathrm{~mm}$ of defect resolution was reported by Chitsazi et al.$^{[17]}$ in ABG treated defects. Formation of new bone in sites grafted by ABG follows a resorption which occurs when osteoblasts deposit osteoid on the bone surfaces which is subsequently mineralized. The hematoma formed around the implanted ABG sites is followed by necrosis which stimulates a local inflammatory response converting into a fibrovascular stroma. It is this connective tissue that conveys recipient derived blood vessels and osteoprogenic precursor cells to the graft. ${ }^{[20]}$ The literature is deficit in revealing the histological events for bone formation in PRF treated IBDs. Nevertheless, He et al..$^{[22]}$ in an in vitro study reported the superiority of PRF in the expression of alkaline phosphatase and induction of mineralization, caused markedly by release of TGF- $\beta 1$ and PDGF-AB.

Handling of the PRF obtained, and its procurement is an important factor to preserve the regenerative potential of this living biomaterial. ${ }^{[23]}$ Although, studies regarding the use of dry glass or glass coated plastic tube and compression of the PRF clot (forcible/ soft) did not seem to influence the architecture of this autologous biomaterial, but careful analysis of both the parameters as advocated by Dohan et al., ${ }^{[24]}$ and to avoid any architectural disintegrity of the fibrin bulk, for the present study, neither the compression of the gel nor the plastic tubes were used.

The ABG obtained by the use of the bone scrapper gets collected in the chamber below the blade. The procedure of retrieving the graft so collected by 
removal of the blade should be managed by utmost care since the removal of the blade by a jerk may lead to an accidental spillover of the graft material. Sometimes, when the adjacent surgical site is deficient in thickness of the cortical bone, a second donor surgical site, e.g. exostosis, maxillary tuberosity and tori can be utilized for ABG procurement. ${ }^{[25]}$

Furthermore, while handling both autologous PRF and autogenous ABG utmost care should be taken to avoid dehydration of the procured graft material. Even refrigeration of the material procured may affect the regenerative potentials. Hence, the time interval between the procurement and the placement of the graft in IBDs should be minimized. ${ }^{[26,27]}$ For the present study, table top portable centrifugal machine was placed adjacent to the dental chair for the procurement of PRF. Recently, centrifugal machine with PRF box (Process Ltd., Nice, France) for dental use has been designed and is commercially available. ${ }^{[28]}$

The bivariate correlation results obtained revealed that any of the two radiographic techniques (IOPA and OPG) can be used for analysis for the regenerative therapy in IBDs. While comparing TGP as the clinical technique with radiographic techniques for measuring the BD level, results obtained give a variable correlation, with a slight inclination toward IOPA as compared to OPG. The radiographic technique using extension cone paralleling instrument for IOPA permits standardization with high repeatability and accuracy in posterior radiographic records. ${ }^{[29]}$

\section{Limitations of the study}

Limitation of the clinical regeneration studies, such as the present one, is inability to assess the histological characteristics of the repaired tissue. Studies to examine the histological nature of the interface of a treated bony defect and the root surface are difficult to conduct for ethical reasons ${ }^{[30]}$ as well as due to possibility of subsequent loss of alveolar bone. ${ }^{[31]}$ Another limitation of the study was the sample size; a larger sample size might have demonstrated statistically significant differences between two groups.

\section{Clinical significance}

Although, our results are based on single-centered study with a small sample size; and long term, multi-centered randomized, controlled clinical trials are further required, nevertheless results of the present study demonstrates that the use of autologous PRF and autogenous ABG were effective in the treatment of three wall IBD with an uneventful healing of the sites. As both ABG and PRF are obtained from patient itself without any concern of immunogenic reactions, ${ }^{[32,33]}$ one from the adjacent surgical site and another one from patients own blood, which decreases the cost of regeneration therapy and time both for the surgeon as well as for the patient. Further, absence of addition of any chemical or biomodifiers, eliminates the possibility of disease transmission, ethical issues, and factors that may influence the regenerative potential.

\section{ACKNOWLEDGEMENT}

The authors thank Saraswati Dental College, Lucknow, India for providing infrastructural support for the conduct of the study.

\section{REFERENCES}

1. Smukler H, Capri D, Landi L. Harvesting bone in the recipient sites for ridge augmentation. Int J Periodontics Restorative Dent 2008;28:411-9.

2. Choukroun J, Adda F, Schoeffler C, Vervelle A. An opportunite' in paro-implantology: The PRF (in French). Implantodonitie 2001;42:55-62.

3. Dohan DM, Choukroun J, Diss A, Dohan SL, Dohan AJ, Mouhyi J, et al. Platelet-rich fibrin (PRF): A second-generation platelet concentrate. Part II: Platelet-related biologic features. Oral Surg Oral Med Oral Pathol Oral Radiol Endod 2006;101:e45-50.

4. Miller SC. Textbook of Periodontia. $3^{\text {rd }}$ ed. Philadelphia: The Blakeston Co.; 1950.

5. Choukroun J, Diss A, Simonpieri A, Girard MO, Schoeffler C, Dohan SL, et al. Platelet-rich fibrin (PRF): A second-generation platelet concentrate. Part IV: Clinical effects on tissue healing. Oral Surg Oral Med Oral Pathol Oral Radiol Endod 2006;101:e56-60.

6. Available from: http://www.maxilon.com/ebner_Grafter/usersguide. pdf. [Last accessed on 2014 Dec 30].

7. Silness J, Loe H. Periodontal disease in pregnancy. Acta Odontal Scand 1964;22:747-59.

8. Loe H, Silness J. Periodontal disease in pregnancy. Acta odontal Scand 1963;21:533-51.

9. Isidor F, Karring T, Attström R. Reproducibility of pocket depth and attachment level measurements when using a flexible splint. J Clin Periodontol 1984;11:662-8.

10. Ursell MJ. Relationships between alveolar bone levels measured at surgery, estimated by transgingival probing and clinical attachment level measurements. J Clin Periodontol 1989;16:81-6.

11. Parashis AO, Polychronopoulou A, Tsiklakis K, Tatakis DN. Enamel matrix derivative in intrabony defects: Prognostic parameters of clinical and radiographic treatment outcomes. J Periodontol 2012;83:1346-52.

12. Shetty SK, Pradeep AR, Deshmukh VL. Use of autologous Platelet rich plasma in the treatment of intrabony defects. J Int Clin Dent Res Organ 2009;1:18-31.

13. Sharma A, Pradeep AR. Treatment of 3-wall intrabony defects in patients with chronic periodontitis with autologous platelet-rich fibrin: A randomized controlled clinical trial. J Periodontol 2011;82:1705-12.

14. Thorat M, Pradeep AR, Pallavi B. Clinical effect of autologous platelet-rich fibrin in the treatment of intra-bony defects: A controlled clinical trial. J Clin Periodontol 2011;38:925-32.

15. Czuryszkiewicz-Cyrana J, Banach J. Autogenous bone and platelet-rich plasma (PRP) in the treatment of intrabony defects. Adv Med Sci 2006;51 Suppl 1:26-30.

16. Blumenthal NM, Alves ME, Al-Huwais S, Hofbauer AM, Koperski RD. 
Defect-determined regenerative options for treating periodontal intrabony defects in baboons. J Periodontol 2003;74:10-24.

17. Chitsazi MT, Shirmohammadi A, Faramarzie M, Pourabbas R, Rostamzadeh An. A clinical comparison of nano-crystalline hydroxyapatite (Ostim) and autogenous bone graft in the treatment of periodontal intrabony defects. Med Oral Patol Oral Cir Bucal 2011;16:e448-53.

18. Takei HH, Carranza FA. The periodontal flap. In: Newman MG, Takei HH, Klokkevold PR, Carranza FA. editors. Clinical Periodontology: A South Asia Edition. New Delhi: Elsevier Saunders; 2011. p. 550-5.

19. Shirmohammadi A, Chitsazi MT, Lafzi A. A clinical comparison of autogenous bone graft with and without autogenous periodontal ligament graft in the treatment of periodontal intrabony defects. Clin Oral Investig 2009;13:279-86.

20. Friedlaender GE. Current concepts review bone grafts. J Bone Joint Surg 1987;69:786-90.

21. Dohan DM, Choukroun J, Diss A, Dohan SL, Dohan AJ, Mouhyi J, et al. Platelet-rich fibrin (PRF): A second-generation platelet concentrate. Part III: leucocyte activation: A new feature for platelet concentrates? Oral Surg Oral Med Oral Pathol Oral Radiol Endod 2006;101:e51-5.

22. He L, Lin $\mathrm{Y}, \mathrm{Hu} \mathrm{X}$, Zhang $\mathrm{Y}, \mathrm{Wu} \mathrm{H}$. A comparative study of platelet-rich fibrin (PRF) and platelet-rich plasma (PRP) on the effect of proliferation and differentiation of rat osteoblasts in vitro. Oral Surg Oral Med Oral Pathol Oral Radiol Endod 2009;108:707-13.

23. Aroca S, Keglevich T, Barbieri B, Gera I, Etienne D. Clinical evaluation of a modified coronally advanced flap alone or in combination with a platelet-rich fibrin membrane for the treatment of adjacent multiple gingival recessions: A 6-month study. J Periodontol 2009;80:244-52.

24. Dohan Ehrenfest DM, Del Corso M, Diss A, Mouhyi J, Charrier JB. Three-dimensional architecture and cell composition of a Choukroun's platelet-rich fibrin clot and membrane. J Periodontol 2010;81:546-55.

25. Mellonig JT. Autogenous and allogenic bone grafts in periodontal therapy. Crit Rev Oral Biol Med 1992;3:333-52.

26. Su CY, Kuo YP, Tseng YH, Su CH, Burnouf T. In vitro release of growth factors from platelet-rich fibrin (PRF): A proposal to optimize the clinical applications of PRF. Oral Surg Oral Med Oral Pathol Oral Radiol Endod 2009;108:56-61.

27. Gupta V, Bains VK, Singh GP, Mathur A. Regenerative potential of platelet rich fibrin in dentistry: Literature review. Asian J Oral Health Allied Sci 2011;1:22-8.

28. Toffler M, Toscano N, Holtzclaw D, Del Corso M, Dohan Ehrenfest DM. Introducing Choukrouns's platelet rich fibrin (PRF) to the reconstructive surgery milieu. J Implant Adv Clin Dent 2009;6:21-32.

29. Inocêncio Faria A, Gallas Torreira M, López Ratón M. Repeatability and accuracy of a paralleling technique for radiographic evaluation of distal bone healing after impacted third molar surgery. Dentomaxillofac Radiol 2013;42:78022535.

30. Stahl SS, Froum SJ, Kushner L. Healing responses of human intraosseous lesions following the use of debridement, grafting and citric acid root treatment. II. Clinical and histologic observations: One year postsurgery. J Periodontol 1983;54:325-38.

31. Keles GC, Sumer M, Cetinkaya BO, Tutkun F, Simsek SB. Effect of autogenous cortical bone grafting in conjunction with guided tissue regeneration in the treatment of intraosseous periodontal defects. Eur J Dent 2010;4:403-11.

32. Sumer M, Keles GC, Cetinkaya BO, Balli U, Pamuk F, Uckan S. Autogenous cortical bone and bioactive glass grafting for treatment of intraosseous periodontal defects. Eur J Dent 2013;7:6-14.

33. Subramaniam P, Kumar K, Ramakrishna T, Bhadranna A. Bone regeneration with plasma-rich-protein following enucleation of traumatic bone cyst. Eur J Dent 2013;7:377-81.

\begin{tabular}{|l|l|}
\hline \multicolumn{2}{|c|}{ Access this article online } \\
\hline Quick Response Code: & Website: \\
& www.eurjdent.com \\
\cline { 2 - 3 } & \\
\hline
\end{tabular}

